\title{
Legislative Approaches to the Electronic Document Definition and its Evidentiary Value in the CIS Countries
}

\author{
${ }^{1}$ Nikolai M. Golovanov, ${ }^{2}$ Anna A. Kulikova, ${ }^{3}$ Oksana V. Shmalij, ${ }^{4}$ Sergey V. Tychinin, ${ }^{5}$ Aleksandr D. \\ Hlebnikov \\ ${ }^{1}$ Saint-Petersburg State University of Architecture and Civil Engineering, 2nd Krasnoarmeyskaya Str., 4, St. \\ Petersburg, 190005, Russia \\ ${ }^{2}$ The Institute of Service Sector and Entrepreneurship (Branch) of DSTU in Shakhty, 147 Shevchenko Street, \\ Shakhty, Rostov Oblast, 346500, Russia \\ ${ }^{3}$ Russian Presidential Academy of National Economy and Public Administration, 82, Vernadskogo Ave., Moscow, \\ 119571, Russia \\ ${ }^{4,5}$ Belgorod State University, 85, Pobedy Street, Belgorod, Belgorod Region, 308015, Russia \\ Email: kgipp@spbgasu.ru
}

Received: $16^{\text {th }}$ May 2018, Accepted: 04 ${ }^{\text {th }}$ June 2018, Published: 30 ${ }^{\text {th }}$ June $_{2018}$

\begin{abstract}
This article considers the issues related to the electronic document definition according to the legislation of the member states of the Commonwealth of Independent States. Attention is focused on differences in the approaches to the structure of the electronic document, the electronic digital signature, the copy of electronic document, the use of electronic documents and electronic materials as evidence in the civil process.
\end{abstract}

Keywords: Electronic Document, Electronic Material, Simple Electronic Signature, Enhanced Unqualified Electronic Signature, Enhanced Qualified Electronic Signature, Evidence, Copy of Electronic Document, Information System, Electronic Document Management.

\section{Introduction}

With the development of computer technology and information technologies, the electronic document has taken significant positions in the field of civil transactions. In the international legal practice, an electronic document was legally applied and legislated in the second half of the XX century. Thus, according to the US Law of the State of Utah dated 1995 "On Digital Signature" (Article 46-3-402), the documents signed by an electronic signature have the same evidentiary power [1]. Similar norms are fixed in most European countries. The European Union has the Decree of the European Parliament dated July 23, 2014 No. 910/2014 "Regulation in the Field of Electronic Identification and Trusted Services for Electronic Transactions in the Domestic Market" [2]. The experience of the said law and order is very valuable for the countries with a transitional economy, introducing the electronic document management at various levels. The CIS legislation lacks a universal approach to defining the concept of "electronic document". There are different definitions that are differently interpreted. Due to the historically established economic relations, the issue of the electronic document unified definition is relevant for legal science. The legal non-development of an electronic document is in obvious imbalance with the wide use of electronic documents and an electronic digital signature [16].

\section{Methodology}

The methodological basis of this article was made by the general scientific and special methods. We used the following ones from the general scientific methods: dialectical, logical, analysis and synthesis, induction and deduction, etc. We used the following ones among the specific scientific cognition methods: formal-legal, comparative-legal, system-structural.

\section{Discussion and Result}

In the Republic of Armenia, the law "On Electronic Document and Electronic Digital Signature" states that the electronic document is the information or a message submitted in the electronic form (Article 2) [3]. In the republics of Belarus, Kazakhstan, Kyrgyzstan, the similar laws state that the electronic document is respectively:

- An electronic document, containing the details allowing to establish its integrity and authenticity (Article 1) [4];

- A document, where the information is given in the electronic digital form and certified by means of an electronic digital signature (Article 1, clause 12) [5]; - An electronic document or an electronic message, having the attributes for identifying it as a document (Article 2) [6].

The laws of the Republics of Turkmenistan and Tajikistan "On Electronic Document" [9, 8] state that it is the information recorded on a computer medium and certified with an electronic digital signature (Article 1 and clause 2 of Article 1).

The law of the Republic of Azerbaijan "On Electronic 
Signature and Electronic Document" specifies that an electronic document is a document for use in the information system, presented in electronic form and confirmed by an electronic signature (clause 1.1.15. of Part 1 of Article 1) [10].

The detailed definitions of the electronic document are given in the laws of the Republic of Moldova "On Electronic Document and Digital Signature" [7] and the law of the Republic of Uzbekistan "On Electronic Document Management" [11].

The first of these acts understands the electronic document as the information in electronic form, created, structured, processed, transmitted by computer, other electronic devices or software and hardware, signed with a digital signature (Article 5).

The second law defines the electronic document as the information recorded in electronic form, confirmed by an electronic digital signature and having other electronic document details that allow it being identified (Article 5). The same article says that the electronic document is created, processed and stored using technical means and services of information systems and information technologies, that it should be created taking into account the possibility of its perception by the electronic document management participants.

The wordings of the laws referred above were adopted in 2000 (Turkmenistan), 2002 (Tajikistan), 2003 (Kazakhstan), 2004 (Kyrgyzstan, Uzbekistan, Azerbaijan, Moldova), 2005 (Armenia) and 2009 (Belarus), which allowed taking into account the legislative experience in the field of electronic document regulation and developing a single concept, but this did not happen.

In Russia, the term of "electronic document" was first used in the Federal Law dated January 10, 2002 No. 1FZ "On Electronic Digital Signature", where it was stated that the electronic document was a document where the information was presented in digital form. This definition was clarified by the Federal Law dated July 27, 2006 No. 149-FZ "On Information, Information Technologies and Information Protection" (hereinafter referred to as the Law "On Information"). Clause 11.1 of Article 2 of the said law states that the electronic document is understood as the documented information submitted in the electronic form, that is, in a form suitable for human perception using the electronic computers, as well as for transmission through the information and telecommunications networks or processing in the information systems.

The above definition has a number of shortcomings: firstly, it does not disclose the concept of "documented information"; secondly, it is used the wording concerning the electronic computers, which does not reflect the possibility of using other information technologies to submit information in the electronic form; thirdly, it points only at the information transfer and processing in the electronic form, which narrows the scope of electronic document management, excludes the creation of electronic information, its storage and copying. The Russian version of the electronic document definition has nothing about its identification. In this regard, it is necessary to apply for clarifications to the standardizing by-laws, [12] where it is stated that the electronic document should consist of two parts: detailed, containing the identification attributes (name, time, place of creation, author's data, etc.), electronic digital signature, and content, including textual, numerical and/or graphic information processed as a whole.

In a number of CIS countries, general issues concerning the electronic document structure are fixed in the law. It seems that this approach is more preferable than it is in Russia. Thus, the mentioned laws of the republics of Tajikistan [8] and Kyrgyzstan [6] reflect that the electronic document consists of two integral parts: general and special. The general part of the electronic document includes information, which is the document content, and information about the addressee. The special part includes one or several electronic digital signatures (Article 7 and Articles 24 , respectively). A similar wording is contained in the law of the Republic of Belarus [4] with that a special part may contain additional data necessary for checking electronic the digital signature(-s) and identifying the electronic document that are established by the technical regulations (Article 17).

As for the electronic signatures, these issues are regulated at the legislative level in Russia, unlike the CIS countries. The Federal Law dated April 6, 2011 No. 63-FZ "On Electronic Signature" establishes the following types: simple electronic signature and enhanced electronic signature. The latter is subdivided into an enhanced unqualified electronic signature (hereinafter referred to as the unqualified electronic signature) and enhanced qualified electronic signature (hereinafter referred to as the qualified electronic signature)

1 of Article 5).

The simple electronic signature allows confirming the fact of the electronic signature formation by a certain person through the use of codes, passwords or other means. The unqualified electronic signature is formed as a result of cryptographic information transformation using the electronic signature key and the electronic signature means. This allows not only identifying the person who has signed the electronic document, but also finding out the fact of making changes to the electronic document after its signing.

The qualified electronic signature has the same properties as the unqualified one, but differs from the 
latter with a qualified certificate issued by an accredited certifying center, where it is indicated the electronic signature verification key, which is also created and verified with the help of means that have been certified to meet the requirements established in the Law "On Electronic Signature".

Part 1 of Article 4 of the Law "On Electronic Signature" states that the electronic interaction participants can use any kind of electronic signature, if this does not contradict the regulatory legal acts or the agreement between them. Part 3 of the same article specifically points out the inadmissibility of recognizing the electronic signature and (or) the electronic document signed by it as not having legal effect only on the grounds that such an electronic signature has been created not by one's own hand, but using the electronic signature means.

Taking into account the above arguments, it seems possible to give the following definition of the electronic document. The electronic document is the information recorded on an electronic medium, having some details to identify it; the electronic document can be created, processed, stored and transmitted using various electronic means.

Considering the issue on the use of electronic documents and materials as evidence in the civil process, it should be noted that there are no indications of electronic documents as the evidence means in the civil cases in any civil procedural code of the CIS countries. This is due to the fact that, with the exception of Russia, these electronic documents, being printed, are equated to written evidence because of direct instructions to laws on electronic documents. In this regard, it should be noted that, since the contents of an electronic document signed by a simple electronic signature and electronic materials posted on the Internet can be changed or deleted from the information and telecommunications network by the time of case hearing, it is advisable to notarize in advance such electronic documents and materials by falling pack upon the evidence security institution by the notaries.

In the civil process, it is important to distinguish the original document and its copy. In Russia, this issue is resolved as follows.

According to GOST 6.10.4-84 "Unified Documentation Systems", the main distinguishing feature of the original, duplicate and copy of the document is an indication that they are exactly such. If there is no corresponding mark, then it is not possible to distinguish the original, duplicate and copy of the document, because they are all identical in content. But it is unclear how this can be related to the electronic document?

In the CIS countries, this issue is resolved as follows. In the Republic of Belarus, the original electronic document exists only in the electronic form. All identical copies of the electronic document are originals and have equal legal force (Article 19) [4]. A copy of the electronic document is a form of external submission of the electronic document in hard copy certified in accordance with the procedure established by law and indicating that it is a copy of the relevant electronic document. The issue is resolved in the same way in Armenia (articles 5 and 6) [3] and Moldova (Article 7) [7].

In Uzbekistan, the original electronic document means every identical copy thereof, subject to authenticity confirmation (Article 8), and a copy means the text of the electronic document in hard copy certified and stored in accordance with the procedure established by law (Article 9) [9].

In Kyrgyzstan, Turkmenistan and Tajikistan, the original electronic document exists only on the computer medium. However, if in Kyrgyzstan a copy of the electronic document means a reproduction of the form of external submission of the electronic document in hard copy, duly certified and bearing an indication that it is a copy (Articles 2-6, 2-7) [5], then in Turkmenistan and Tajikistan, the copy of the electronic document means the information received from the original electronic document, recorded in electronic form on a magnetic medium, separable from the machine one. Each such copy should be certified in accordance with the procedure established by law and contain an indication that it is a copy of the relevant electronic document (Articles 7 and 8) [9, 8]. In Kazakhstan and Azerbaijan, the issue of originals and copies of the electronic document is bypassed in the relevant laws. It is indicated only that the electronic document that meets the requirements of the law and is certified by means of an electronic digital signature of a person authorized to sign it is equivalent to a document signed in hard cope (in accordance with clause 1 of Article 7, clauses 3.4 and 3.5 of Article 3) $[5,10]$.

With regard to the foregoing, we should agree that the electronic document does not have the electronic copies at all. All of its unchanged variants, expressed in the electronic form and signed with an electronic digital signature, are genuine electronic documents, its copies, having equal legal force. And only a paper reproduction, certified by the signature of the authorized person (notary, any person having the right to perform the notarial acts) can act as a copy of the electronic document. Such a copy can also be considered as a copy of the electronic document in hard copy [16].

\section{Conclusions}

Consideration of the use of electronic documents and materials as evidence in the civil process allowed us 
Helix Vol. 8(4): 3503- 3507

making the following conclusions:

- An electronic document is an information object on an electronic medium with details allowing it being identified;

- An electronic signature is the defining criterion in the electronic evidence application;

- An electronic document signed with an enhanced electronic signature can be considered a direct proof when it is used in the civil and arbitration proceedings, since it allows identifying a person who has signed the electronic document and detecting the fact of making changes to it after signing the document;

- An electronic document signed with a simple electronic signature can be considered a direct proof only when it is notarized at the date of signing the document, as this will prevent any changes to the document. Otherwise, the electronic document will be considered as an indirect proof;

- The electronic materials are the materials sent by email and placed on the Internet. They can be considered a direct proof only if the following three conditions are simultaneously observed: identification of a person who sent or posted them on the Internet; exclusion of the fact of changing the material content at the time it was presented as evidence in court; notarization of the information content at the time of its receipt by e-mail or at the time of acquaintance with it on the Internet; in other cases, the electronic materials can be considered only indirect evidence in court.

We would also like to draw attention to the following. In the courts of the CIS countries, the only criterion for the electronic document reliability is the presence of an electronic signature. In the USA, this issue is treated differently. The electronic documents are recognized by courts as admissible evidence not only if they are confirmed by the electronic signature, but by the testimony, written declarations of the electronic document recipient and other indirect evidence [17].

With regard to the increasing use of electronic documents and materials in civil circulation, a large number of regulatory legal acts regulating a particular area of interaction with the electronic documents and materials, the legislators of the CIS countries should also give in the model law not only a legal definition of the electronic document, but the electronic material as well; determine the electronic document structure, the legal status of electronic document management; supplement the list of evidence by indicating the electronic documents and materials; regulate the procedural order for the submission and evaluation of electronic evidence in courts. All this will ensure reliable legal protection of the electronic interaction participants in case of various civil law disputes.

\section{References}

[1] Utah Digital Signature Act. Enacted by L. 1995, ch. 61 // http://www.jus.unitn.it/ users/ pascuzzi/ privcomp9798/dogumento/firma/Utah/udsa.html (accessed 27 March 2018).

[2] Directive on a Community framework for electronic signatures // http://eurlex.europa.eu/eli/reg/2014/910/oj/ (accessed 27 March 2018).

[3] Law of the Republic of Armenia dated January 15, 2005 No. ZR-40 "On Electronic Document and Electronic Digital Signature" // http://docplayer.ru/43002343-Zakonrespubliki-armeniya.html (accessed on March 27, 2018).

[4] Law of the Republic of Belarus dated December 28, 2009 No. 113-Z "On Electronic Document and Electronic Digital Signature" // http://www.pravo.by/pdf/201015/2010-15\%28087-101\%29. pdf (accessed on 27 March 2018).

[5] Law of the Republic of Kazakhstan dated January 7, 2003 No. 370-II "On Electronic Document and Electronic Digital Signature" /I

http://online.zakon.kz/Document/?doc id=1 $\underline{035484}$ (accessed on 27 March 2018).

[6] Law of the Republic of Kyrgyzstan dated July 17, 2004 No. 92 "On Electronic Document and Electronic Digital Signature" // http://www.sti.gov.kg/docs/defaultsource/content/zkrep152017n128.pdf?sfvrsn =2 (accessed on 27 March 2018).

[7] Law of the Republic of Moldova dated July 15, 2004 No. 264-HU "On Electronic Document and Electronic Digital Signature" // http://lex.justice.md/en/313061/ (accessed on 27 March 2018).

[8] Law of the Republic of Tajikistan dated May 10, 2002 No. 51 "On Electronic Document" /l http://www.andoz.tj/ru/uploads/1_№7_electr on-doc-RT_ru.pdf (accessed on $27^{-}$March 2018).

[9] Law of the Republic of Turkmenistan dated December 19, 2000 No. 54-II "On Electronic Document" // http://continent- 
online.com/Document/?doc_id=31342099\#p os $=0 ; 0 \&$ sel_link $=1003437466$ (accessed on 27 March $2 \overline{0} 18$ ).

[10] Law of the Republic of Azerbaijan dated March 9, 2004 No. 602-IIG "On Electronic Document and Electronic Digital Signature" // http://www.taxes.gov.az/modul.php?name= qanun\&news $=286 \&$ lang $=$ rus $($ accessed on 27 March 2018).

[11] Law of the Republic of Uzbekistan dated April 29, 2004 No. 611-II "On Electronic Document Management" // https://nrm.uz/contentf?doc $=58080$ zakon_r espubliki_uzbekistan_ot_29_04_2004_g_n 611-ii ob elektronnom dokumentooborote(accessed on 27 March 2018).

[12] GOST 50.1.021-2001. Recommendations for Standardization. Information Technologies for the Product Life Cycle Support. Technological Dictionary. Part 1. Product Life Cycle Stages (adopted and put into effect by the Decree of the State Standard of the Russian Federation dated July 2, 2001 No. 256-st). M.: Standartinform, 2006. (in Russian)

[13] Bobyleva M.P. 2010. Document Management: From Paper to Electronic. M.: MEHI, 257 p. (in Russian)

[14]Zhenilo V.R., Kirin V.I. 2001. Digital Electronic Document. Collection of the X International Scientific Conference "Information of Law Enforcement Systems". M. "NAKRA PRINT". 449 p. (in Russian)

[15] Semiletov S.I. 1999. The Concept of "Legal Electronic Document" and its Legal Status: Articles and Paper Abstracts. M. p. 7-13. (in Russian)

[16]Halikov R.O. 2005. Electronic Digital Signature and Electronic Document as the Evidence Means in Civil and Arbitration Proceedings. Scientific Notes of the Institute of Social and Humanitarian Knowledge and the Russian International Academy of Tourism. Joint Issue. Kazan. p. 158-173. (in Russian)

[17] Stevenson K.L. Courts Confront Admissibility of Text and Instant Messages //
.1American Bar Association. Litigation News Online. 2008; https://apps.americanbar.org/litigation/litigat ionnews/2008/april/0408_article_messages. html (accessed 27 March 2018). 